\title{
Microstructural Characterization of As-Cast V-Si Alloys and Reevaluation of the Invariant Reactions Involving the Liquid Phase of the V-Si System
}

\author{
Belmira Benedita de Lima-Kühn ${ }^{a, b}$, Antonio Augusto Araujo Pinto da Silva ${ }^{a, c} *$, Paulo Atsushi \\ Suzukia, Gilberto Carvalho Coelho ${ }^{a, d}$, Carlos Angelo Nunes ${ }^{a}$ \\ ${ }^{a}$ Escola de Engenharia de Lorena - EEL, Universidade de São Paulo - USP, Estrada Municipal do \\ Campinho, s/n, 12600-000, Lorena, SP, Brazil \\ ${ }^{b}$ Universidade Federal Rural do Rio de Janeiro - UFRRJ. Rodovia BR 465, Km 7, 23851-970, \\ Seropédica, RJ, Brazil \\ c Instituto de Engenharia Mecânica - IEM, Universidade Federal de Itajubá - UNIFEI, Avenida BPS, \\ 1303, 37500-903, Itajubá, MG, Brazil \\ ${ }^{d}$ Núcleo de Pesquisa - Centro Universitário de Volta Redonda - UniFoa, Avenida Paulo Erlei \\ Alves Abrantes, 1325, 27240-560, Volta Redonda, RJ, Brazil
}

Received: January 02, 2016; Revised: June 27, 2016; Accepted: August 10, 2016

\begin{abstract}
Alloys containing Me-Si-B (Me - Refractory Metal) are of great interest for high temperature structural applications and accurate knowledge of its low order systems (binaries and ternaries) is important to predict the phase relations in the multicomponent alloys. Recent reevaluations of binaries containing Me-Si found out that the accuracy of the description of this type of systems could be improved. Knowing this, a reevaluation of the invariant reactions in the $\mathrm{V}-\mathrm{Si}$ system via microstructural characterization of as-cast alloys is presented. Alloys of key compositions were prepared by arc melting pure V (min. 99.75\%) and $\mathrm{Si}$ (min. 99.998\%) and characterized via scanning electron microscopy (SEM) using back-scattered electron (BSE) mode, energy-dispersive X-ray spectroscopy (EDS) and $\mathrm{X}$-ray diffraction (XRD). The results of this study confirmed the solid phases, the nature of the invariant reactions and determined new compositions for the liquid participating in certain invariant reactions.
\end{abstract}

Keywords: V-Si system, phase diagrams, silicides, solidification.

\section{Introduction}

Accurate description of binaries and ternaries phase diagrams is of fundamental importance for the development of thermodynamic databases to predict phase relations and to define processing conditions for multicomponent alloys.

Reviews of the V-Si system were published by Smith ${ }^{1,2}$ and Schlesinger ${ }^{3}$, consolidating the information available in the literature up to 1981, 1985 and 1990, respectively. All reviews are in good agreement, the following solid phases are considered stable: (V), $\mathrm{V}_{3} \mathrm{Si}_{1} \mathrm{~V}_{5} \mathrm{Si}_{3}, \mathrm{~V}_{6} \mathrm{Si}_{5}, \mathrm{VSi}_{2}$ and $(\mathrm{Si})$. The $(\mathrm{V})$ phase dissolves important amount of $\mathrm{Si}$ while the solubility of $\mathrm{V}$ in $(\mathrm{Si})$ is negligible. The phase $\mathrm{V}_{3} \mathrm{Si}$ has an important range of solubility whereas the $\mathrm{V}_{5} \mathrm{Si}_{3}, \mathrm{~V}_{6} \mathrm{Si}_{5}$ and $\mathrm{VSi}_{2}$ phases are stoichiometric. Smith ${ }^{1}$ initially considered the $\mathrm{V}_{3} \mathrm{Si}$ phase with peritectic formation but the investigation of Jorda and Muller ${ }^{4}$ indicated it as congruent and also established its range of solubility. This new information was taken into account in the latter reviews ${ }^{2,3}$. The compounds $\mathrm{V}_{5} \mathrm{Si}_{3}, \mathrm{VSi}_{2}$ are also formed via congruent transformations while $\mathrm{V}_{6} \mathrm{Si}_{5}$ is a product of a peritectic reaction $\left(\mathrm{L}+\mathrm{V}_{5} \mathrm{Si}_{3}\right.$ $\leftrightarrow \mathrm{V}_{6} \mathrm{Si}_{5}$ ), decomposing eutectoidically at lower temperature $\left(\mathrm{V}_{6} \mathrm{Si}_{5} \leftrightarrow \mathrm{V}_{5} \mathrm{Si}_{3}+\mathrm{VSi}_{2}\right)$. Four eutectics reactions are found in this system: (1) $\mathrm{L} \leftrightarrow(\mathrm{V})+\mathrm{V}_{3} \mathrm{Si}$; (2) $\mathrm{L} \leftrightarrow \mathrm{V}_{3} \mathrm{Si}+\mathrm{V}_{5} \mathrm{Si}_{3}$;

* e-mail: aaaps@usp.br
(3) $\mathrm{L} \leftrightarrow \mathrm{V}_{6} \mathrm{Si}_{5}+\mathrm{VSi}_{2}$; (4) $\mathrm{L} \leftrightarrow \mathrm{VSi}_{2}+(\mathrm{Si})$. Table 1 shows the crystallographic data for the stable solid phases of this system. Zhang et al. ${ }^{5}$ assessed the V-Si system taking into account the available data for phase equilibria and thermodynamic properties and also performed differential thermal analysis (DTA) experiments. Their optimization is in good agreement with the phase diagram proposed by $\mathrm{Smith}^{2}$. Figure 1 shows the superposition of the V-Si phase diagram proposed by $\mathrm{Smith}^{2}$ and that calculated by Zhang et al. ${ }^{5}$ where the vertical lines indicate the nominal compositions of the alloys prepared in this work.

Recent investigations carried out in our group ${ }^{6-10}$ have contributed to better description of phase diagrams of several Me-Si (Me-metal) binaries, revealing the need to reevaluate the phase relations in these systems. Thus, in this work the invariant reactions involving the liquid phase of the V-Si system have been reevaluated via microstructural characterization of as-cast alloys.

\section{Experimental Procedure}

V-Si alloys with masses between 2 and $8 \mathrm{~g}$ were prepared by arc melting V (min. 99.8 wt.\%) and $\mathrm{Si}$ (min. 99.998 wt.\%) under argon ( $\min .99 .995 \%$ ) in a water-cooled copper hearth using non-consumable tungsten electrode and $\mathrm{Ti}$ 
Table 1: Crystallographyc data ${ }^{11}$ of the stable solid phases in the V-Si system.

\begin{tabular}{lcccc}
\hline Phase & Pearson symbol & Space Group & Strukturbericht designation & Prototype \\
\hline$(\mathrm{V})$ & $\mathrm{cI} 2$ & $\mathrm{Im}-3 \mathrm{~m}$ & $\mathrm{~A} 2$ & $\mathrm{~W}$ \\
$\mathrm{~V}_{3} \mathrm{Si}$ & $\mathrm{cP} 8$ & $\mathrm{Pm}-3 \mathrm{~m}$ & $\mathrm{~A} 15$ & $\mathrm{Cr}_{3} \mathrm{Si}$ \\
$\mathrm{V}_{5} \mathrm{Si}_{3}$ & $\mathrm{I} 4 / \mathrm{mcm}$ & $\mathrm{D} 8_{\mathrm{m}}$ & $\mathrm{W}_{5} \mathrm{Si}_{3}$ \\
$\mathrm{~V}_{6} \mathrm{Si}_{5}$ & $\mathrm{tI} 32$ & $\mathrm{Immm}$ & $\ldots$ & $\mathrm{V}_{6} \mathrm{Si}_{5}$ \\
$\mathrm{VSi}_{2}$ & $\mathrm{oI} 44$ & $\mathrm{P} 622$ & $\mathrm{C} 40$ & $\mathrm{CrSi}_{2}$ \\
$(\mathrm{Si})$ & $\mathrm{hP9}$ & $\mathrm{Fm}-3 \mathrm{~m}$ & $\mathrm{~A} 4$ & $\mathrm{C}$ (Diamond) \\
\hline
\end{tabular}

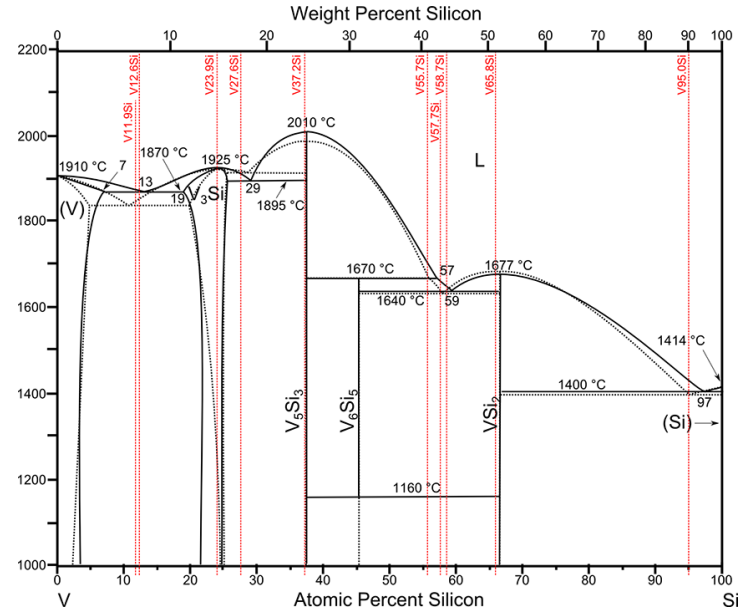

Figure 1: V-Si Phase Diagram proposed by $\mathrm{Smith}^{2}$ (solid lines) and Zhang et al. ${ }^{5}$ (dashed lines). Vertical lines indicate the assumed compositions of the alloys prepared in this work.

getter. Five melting steps were carried out for each alloy to produce chemically homogeneous samples. After melting the alloys were weighted to evaluate possible mass losses during arc melting.

The alloys were characterized through scanning electron microscopy (SEM) in the back-scattered electron mode (BSE), Energy-Dispersive X-ray Spectroscopy (EDS) and $\mathrm{X}$-ray diffraction (XRD).

For the SEM/EDS analyses the alloys were hot mounted in resin, ground with $\mathrm{SiC}$ abrasive paper (\#120 $\rightarrow$ \#4000) and polished with colloidal silica suspension (OP-S). The images were obtained in a 1450VP (LEO) and TM3000 (Hitachi) SEM instruments. The EDS analyses were carried out using a Swift ED3000, Oxford Instruments.

For the XRD experiments, the as-cast alloys were mechanically ground and sieved to below 80 Mesh $(177 \mu \mathrm{m})$. The measurements were carried out at room temperature using $\mathrm{Ni}$-filtered $\mathrm{Cu}-\mathrm{K} \alpha$ radiation in an Empyrean (Panalytical) diffractometer. The measurement conditions were $20^{\circ}<2 \theta<90^{\circ}$, $0.02^{\circ}$ step. The phases were identified based on Villars and Calvert crystallographic data ${ }^{11}$ and the Powder Cell software ${ }^{12}$.

The liquid compositions of the invariant reactions were estimated based on the microstructure of the alloys: either according to the transitions of primary precipitation between two consecutive samples or when the microstructure of the sample was $100 \%$ eutectic. In the first case the estimated composition for the liquid is the average between the calculated compositions attributing the mass loss to $\mathrm{Si}$ in the two consecutive samples. In the second case it is the average between the nominal composition and the calculated one attributing mass loss to $\mathrm{Si}$.

\section{Results and Discussion}

The results will be presented according to the Si contents of the alloys, from the lowest to the highest. Table 2 shows the chemical compositions of the alloys prepared in this work, i.e. their nominal composition and their composition range based on the mass losses occurred during the arc melting (attributing all the mass losses to either $\mathrm{V}$ or $\mathrm{Si}$ ). In the following text as well as in Figure 1, the alloys are referred to their calculated compositions attributing all the mass losses to Si vaporization (column 4 of Table 2). Table 3 indicates the phases present in each alloys, as determined via XRD.

The XRD results of V11.9Si and V12.6Si alloys have indicated the presence of $(\mathrm{V})$ and $\mathrm{V}_{3} \mathrm{Si}$ in their microstructure. Figure $2(a, b)$ shows SEM/BSE micrograph of these alloys where an eutectic formed by (V) and $\mathrm{V}_{3} \mathrm{Si}$ is observed in both of them. However, the V11.9Si alloy presents primary precipitation of $(\mathrm{V})$ while $\mathrm{V} 12.6 \mathrm{Si}$ alloy shows primary precipitation of $\mathrm{V}_{3} \mathrm{Si}$. The presence of $(\mathrm{V})$ primary precipitates in V11.9Si alloy and of $\mathrm{V}_{3} \mathrm{Si}$ in V12.6Si alloy indicates that the liquid eutectic composition is in the $11.9-12.6$ at.\% $\mathrm{Si}$ (i.e. $12.3 \pm 0.3$ at. $\% \mathrm{Si}$ ) interval, which is between 10.8 assessed by Zhang et al. ${ }^{5}$ and 13 at.\% proposed by Smith ${ }^{2}$.

The XRD results of V23.9Si alloy have shown only $\mathrm{V}_{3} \mathrm{Si}$ phase in the microstructure of this alloy, confirmed by single-phase observation in the SEM/BSE analysis. This result confirms the congruent formation of $\mathrm{V}_{3} \mathrm{Si}$ phase, in agreement with the proposal of Smith ${ }^{2}$ and Zhang et al. ${ }^{5}$.

The XRD results of the V27.6Si alloy have indicated the presence of $\mathrm{V}_{3} \mathrm{Si}$ and $\mathrm{V}_{5} \mathrm{Si}_{3}$ phases in its microstructure. Figure 3 shows a SEM/BSE micrograph of this alloy indicating a full eutectic microstructure formed by $\mathrm{V}_{3} \mathrm{Si}$ and $\mathrm{V}_{5} \mathrm{Si}_{3}$. The presence of a $100 \%$ eutectic microstructure in this alloy indicates that the composition of the eutectic liquid is between 27.6 and 28.0 at.\% Si (i.e. $27.8 \pm 0.2$ at.\% $\mathrm{Si}$ ), a value slightly lower than that found by $\mathrm{Smith}^{2}$ but equal to that proposed by Zhang et al. ${ }^{5}$. 
Table 2: Compositions of the alloys produced in this work.

\begin{tabular}{lcccc}
\hline \multicolumn{2}{c}{ Alloy Composition (a) } & Nominal composition (at. \% Si) (b) & Mass loss during arc-melting(\%) & \multicolumn{3}{c}{ Composition Range (at. \% Si) } \\
\hline V11.9Si & 11.96 & 0.02 & 11.93 & 11.97 \\
V12.6Si & 13.00 & 0.28 & 12.57 & 13.03 \\
V23.9Si & 24.00 & 0.09 & 23.89 & 24.02 \\
V27.6Si & 28.02 & 0.36 & 27.61 & 28.11 \\
V37.2Si & 37.50 & 0.33 & 37.19 & 37.60 \\
V55.7Si & 56.01 & 0.54 & 55.68 & 56.24 \\
V57.7Si & 58.01 & 0.60 & 57.67 & 58.27 \\
V58.7Si & 58.97 & 0.42 & 58.74 & 59.15 \\
V65.8Si & 66.70 & 1.96 & 65.85 & 67.63 \\
V95.0Si & 94.98 & 2.55 & 94.84 & 96.39 \\
\hline
\end{tabular}

(a) Adopted composition; (b) composition based on the weighted masses of V and Si, before arc melting; (c) calculated composition attributing mass losses to $\mathrm{Si}$; (d) calculated composition attributing mass losses to $\mathrm{V}$.

Table 3: XRD identification of the phases present in the alloys produced in this work.

\begin{tabular}{lccc}
\hline Alloy & Phase 1 & Phase 2 & Phase 3 \\
\hline $\mathrm{V} 11.9 \mathrm{Si}$ & $(\mathrm{V})$ & $\mathrm{V}_{3} \mathrm{Si}$ & \\
$\mathrm{V} 12.6 \mathrm{Si}$ & $(\mathrm{V})$ & $\mathrm{V}_{3} \mathrm{Si}$ & \\
$\mathrm{V} 23.9 \mathrm{Si}$ & $\mathrm{V}_{3} \mathrm{Si}$ & & \\
$\mathrm{V} 27.6 \mathrm{Si}$ & $\mathrm{V}_{3} \mathrm{Si}$ & $\mathrm{V}_{5} \mathrm{Si}_{3}$ & \\
$\mathrm{~V} 37.2 \mathrm{Si}$ & $\mathrm{V}_{5} \mathrm{Si}_{3}$ & & \\
$\mathrm{~V} 55.7 \mathrm{Si}$ & $\mathrm{V}_{5} \mathrm{Si}_{3}$ & $\mathrm{~V}_{6} \mathrm{Si}_{5}$ & $\mathrm{VSi}_{2}$ \\
$\mathrm{~V} 57.7 \mathrm{Si}$ & $\mathrm{V}_{6} \mathrm{Si}_{5}$ & $\mathrm{VSi}_{2}$ & \\
$\mathrm{~V} 58.7 \mathrm{Si}$ & $\mathrm{V}_{6} \mathrm{Si}_{5}$ & $\mathrm{VSi}_{2}$ & \\
$\mathrm{~V} 65.8 \mathrm{Si}$ & $\mathrm{VSi}_{2}$ & & \\
$\mathrm{~V} 95.0 \mathrm{Si}$ & $\mathrm{VSi}_{2}$ & $(\mathrm{Si}$ & \\
\hline
\end{tabular}

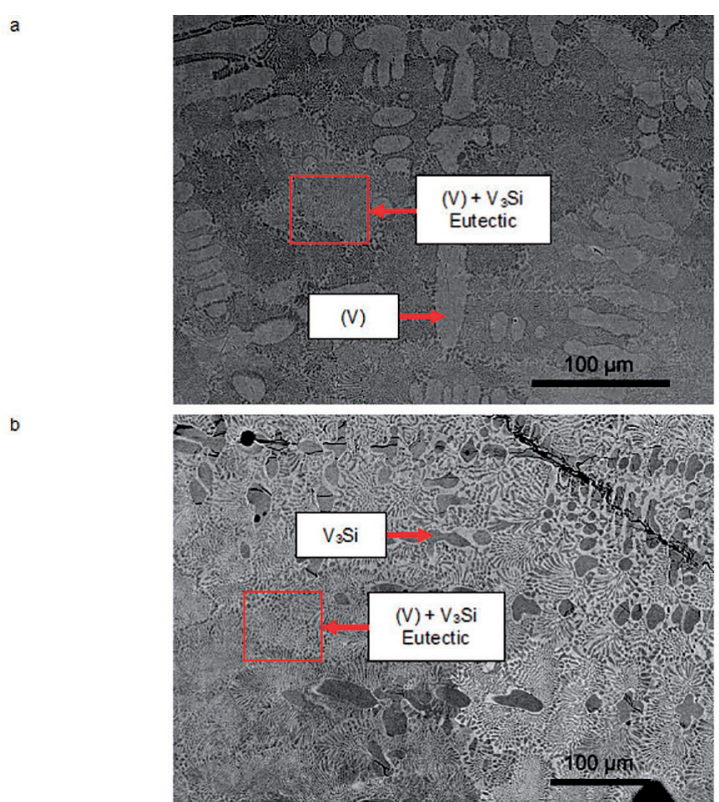

Figure 2: SEM/BSE micrograph of: (a) V11.9Si; (b) V12.6Si as-cast alloys.

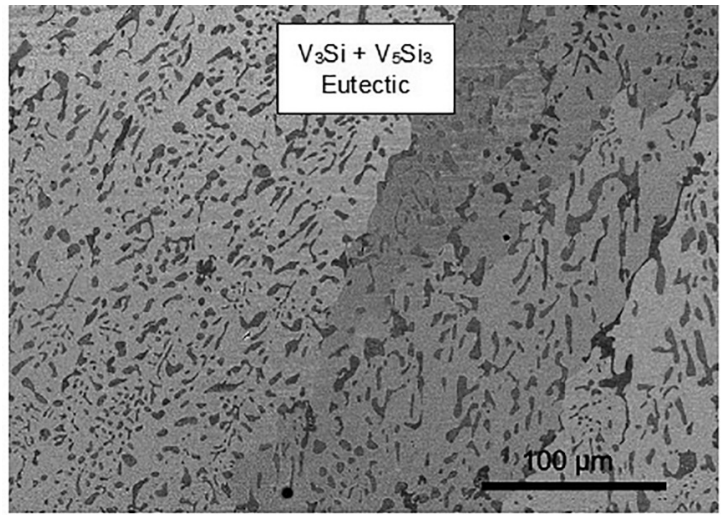

Figure 3: SEM/BSE micrograph of the V27.6Si as-cast alloy.

The XRD results of V37.2Si alloy have indicated only $\mathrm{V}_{5} \mathrm{Si}_{3}$ phase in its microstructure, supported by the SEM/BSE analysis. This result confirms the congruent formation of the $\mathrm{V}_{5} \mathrm{Si}_{3}$ phases, in agreement with $\mathrm{Smith}^{2}$ and Zhang et al. ${ }^{5}$.

Figure 4 shows SEM/BSE micrographs of the V55.7Si (a, b), V57.7Si (c) and V58.7Si (d) alloys. XRD results have indicated the presence of $\mathrm{V}_{6} \mathrm{Si}_{5}$ and $\mathrm{VSi}_{2}$ in all these alloys as well as $\mathrm{V}_{5} \mathrm{Si}_{3}$ in the V55.7Si alloy. SEM/BSE micrographs from all these alloys presented a eutectic formed by $\mathrm{V}_{6} \mathrm{Si}_{5}$ and $\mathrm{VSi}_{2}$ in the last regions to solidify. Alloy V55.7Si micrograph shows small fractions of $\mathrm{V}_{5} \mathrm{Si}_{3}$ primary precipitation and pro-eutectic $\mathrm{V}_{6} \mathrm{Si}_{5}$. The microstructure of V57.7Si alloy presents near fully $\mathrm{V}_{6} \mathrm{Si}_{5}+\mathrm{VSi}_{2}$ eutectic microstructure and few $\mathrm{V}_{6} \mathrm{Si}_{5}$ primary precipitates. The micrograph of $\mathrm{V} 58.7 \mathrm{Si}$ alloy shows primary precipitation of $\mathrm{VSi}_{2}$. The presence of $\mathrm{V}_{5} \mathrm{Si}_{3}$ primary precipitates in the $\mathrm{V} 55.7 \mathrm{Si}$ alloy and $\mathrm{V}_{6} \mathrm{Si}_{5}$ primary precipitates in the V57.7Si alloy suggests that the composition of the liquid in the peritectic reaction involving $\mathrm{V}_{6} \mathrm{Si}_{5}$ is between 55.7 and 57.7 at.\% Si (i.e. $56.7 \pm 1.0$ at.\% $\mathrm{Si}$ ) in accordance (considering the estimated error) with the 57 at.\% proposed by $\mathrm{Smith}^{2}$ and 56.2 at.\% proposed by Zhang et al. ${ }^{5}$. The presence of $\mathrm{V}_{6} \mathrm{Si}_{5}$ primary precipitates in $\mathrm{V} 57.7 \mathrm{Si}$ 
a

$\mathrm{b}$

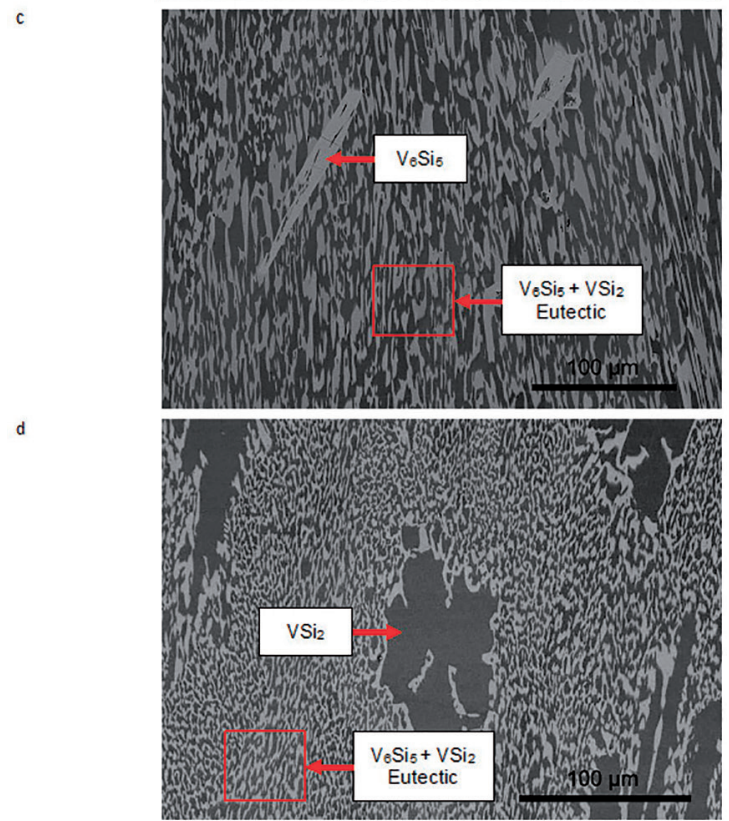

Figure 4: SEM/BSE micrographs of the: (a,b) V55.7Si, (c) V57.7Si and (d) V58.7Si as-cast alloys. alloy and $\mathrm{VSi}_{2}$ primary precipitates in $\mathrm{V} 58.7 \mathrm{Si}$ alloy indicates that the composition of the liquid in the $\mathrm{V}_{6} \mathrm{Si}_{5}+\mathrm{VSi}_{2}$ eutectic is between 57.7 and 58.7 at.\% $\mathrm{Si}$ (i.e. $58.2 \pm 0.5$ at.\% $\%$ Si). Our proposed composition for the eutectic liquid is between 57.6 (assessed by Zhang et al. ${ }^{5}$ ) and 59 at.\% (proposed by Smith ${ }^{2}$ ).

The XRD results of V65.8Si alloy have indicated only the $\mathrm{VSi}_{2}$ phase. The SEM/BSE micrographs of this alloy have shown a major $\mathrm{VSi}_{2}$ microstructure, confirming the congruent formation of $\mathrm{VSi}_{2}$ as proposed by $\mathrm{Smith}^{2}$ and Zhang et al. ${ }^{5}$.

The XRD results of the V95.0Si alloy have indicated the presence of $\mathrm{VSi}_{2}$ and $(\mathrm{Si})$ in its microstructure. Figure 5 shows a SEM/BSE micrograph of this alloy with a fully eutectic microstructure formed by $\mathrm{VSi}_{2}$ and $(\mathrm{Si})$. The presence of a $100 \%$ eutectic microstructure indicates that the composition of the liquid in the $\mathrm{VSi}_{2}+(\mathrm{Si})$ eutectic is between 94.8 and 95.0 at.\% Si (i.e. $94.9 \pm 0.1$ at.\% Si). Our proposal for the liquid composition is richer in $\mathrm{V}$ than the 97 at.\% proposed by Smith $^{2}$ but in agreement with the assessment of Zhang et al. ${ }^{5}$.

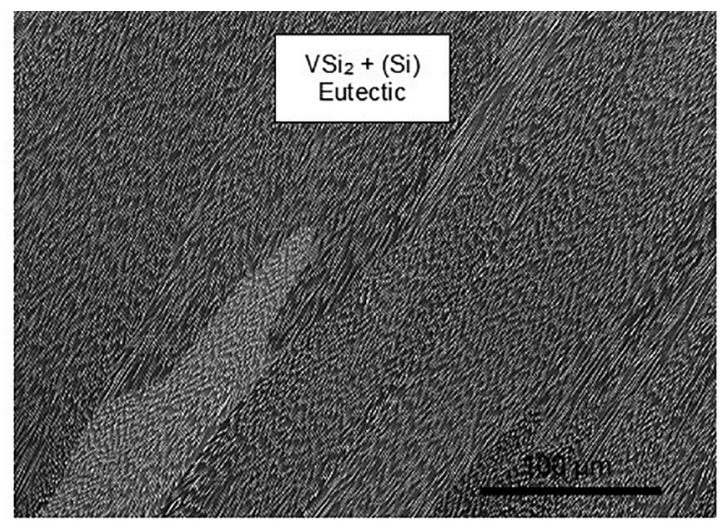

Figure 5: SEM/BSE micrograph of the V95.0Si as-cast alloy.

The microstructural analysis of these alloys, therefore, confirms all the solid phases and invariant reactions in the V-Si phase diagram. The proposal for the liquid phase compositions in the invariant reactions is summarized in Table 4.

\section{Conclusions}

The results of microstructural characterization (SEM/BSE $+\mathrm{EDS}+\mathrm{XDR}$ ) of the as-cast V-Si alloys investigated in this

Table 4: Liquid compositions at invariant reactions in the V-Si system.

\begin{tabular}{lccc}
\hline Invariant reaction & $\begin{array}{c}\text { Liquid Composition, at.\% Si } \\
\text { Zhang et al. }\end{array}$ & $\begin{array}{c}\text { Liquid Composition, at.\% Si } \\
\text { Smith }\end{array}$ & $\begin{array}{c}\text { Liquid Composition, at.\% Si } \\
\text { This work }\end{array}$ \\
\hline $\mathrm{L} \leftrightarrow(\mathrm{V})+\mathrm{V}_{3} \mathrm{Si}$ & 10.8 & 13 & $12.3 \pm 0.3$ \\
$\mathrm{~L} \leftrightarrow \mathrm{V}_{3} \mathrm{Si}$ & 25 & $\sim 24(\mathrm{a})$ & Not evaluated \\
$\mathrm{L} \leftrightarrow \mathrm{V}_{3} \mathrm{Si}+\mathrm{V}_{5} \mathrm{Si}_{3}$ & 27.8 & 229 & $27.8 \pm 0.2$ \\
$\mathrm{~L} \leftrightarrow \mathrm{V}_{5} \mathrm{Si}_{3}$ & 37.5 & 37.5 & Not evaluated \\
$\mathrm{L}+\mathrm{V}_{5} \mathrm{Si}_{3} \leftrightarrow \mathrm{V}_{6} \mathrm{Si}_{5}$ & 56.2 & 57 & $56.7 \pm 1.0$ \\
$\mathrm{~L} \leftrightarrow \mathrm{V}_{6} \mathrm{Si}_{5}+\mathrm{VSi}_{2}$ & 57.6 & $\sim 59$ & $58.2 \pm 0.5$ \\
$\mathrm{~L} \leftrightarrow \mathrm{VSi}_{2}$ & 66.7 & 66.7 & Not evaluated \\
$\mathrm{L} \leftrightarrow \mathrm{VSi}_{2}+(\mathrm{Si})$ & 94.7 & 97 & $94.9 \pm 0.1$ \\
\hline
\end{tabular}

(a) Approximate value obtained by reading the phase diagram 
study confirmed the solid phases, the nature of the invariant reactions and determined new compositions for the liquid participating in certain invariant reactions of this system. The compositions of the liquid phase that participates in the invariant reactions are suggested as: (1) In the (V) $+\mathrm{V}_{3} \mathrm{Si}$ eutectic the liquid composition is 12.3 at. $\% \mathrm{Si}$; (2) In the $\mathrm{V}_{3} \mathrm{Si}$ $+\mathrm{V}_{5} \mathrm{Si}_{3}$ eutectic the liquid composition is 27.8 at.\% $\mathrm{Si}$; (3) In the $\mathrm{V}_{5} \mathrm{Si}_{3}+\mathrm{L}$ peritectic the liquid composition is 56.7 at. $\%$ $\mathrm{Si}$; (4) In the $\mathrm{V}_{3} \mathrm{Si}+\mathrm{V}_{5} \mathrm{Si}_{3}$ eutectic the liquid composition is 58.2 at. $\% \mathrm{Si}$; and finally in (5) In the $\mathrm{VSi}_{2}+(\mathrm{Si})$ eutectic the liquid composition is 94.9 at.\% Si.

\section{Acknowledgements}

Belmira Benedita de Lima-Kühn acknowledges CAPES for the financial support. The authors also acknowledge Wah Chang (Albany, OR, USA) for providing the vanadium used in this work.

\section{References}

1. Smith JF. The Si-V (Silicon-Vanadium) System. Bulletin of Alloy Phase Diagrams. 1981;2(21):42-48.

2. Smith JF. The Si-V (Silicon-Vanadium) system: Addendum. Bulletin of Alloy Phase Diagrams. 1985;6(3):266-271.

3. Schlesinger ME. Thermodynamics of solid transition-metal silicides. Chemical Reviews. 1990;90(4):607-628

4. Jorda JL, Muller J. The $\mathrm{V}_{3} \mathrm{Si}$ phase: Type of formation and homogeneity range. Journal of the Less Common Metals. 1982;84:39-48.
5. Zhang C, Du Y, Xiong W, Xu H, Nash P, Ouyang Y, et al. Thermodynamic modeling of the $\mathrm{V}-\mathrm{Si}$ system supported by key experiments. Calphad. 2008;32(2):320-325.

6. da Silva AAAP, Ramos ECT, Faria MIST, Coelho GC, Nunes CA. The Ta-Si System: Reevaluation of the Liquid Compositions in the Invariant Reactions and Determination of the Invariant Reaction Involving Both $\beta \mathrm{Ta}_{5} \mathrm{Si}_{3}$ and $\alpha \mathrm{Ta}_{5} \mathrm{Si}_{3}$ Phases. Journal of Phase Equilibria and Diffusion. 2015;36(3):209-217.

7. Gigolotti JCJ, Nunes CA, Suzuki PA, Coelho GC. Evaluation of Phase Equilibria Involving the Liquid Phase in the Hf-Si System. Journal of Phase Equilibria and Diffusion. 2014;35(5):622-630.

8. Chad VM, Faria MIST, Coelho GC, Nunes CA, Suzuki PA. Microstructural characterization of as-cast $\mathrm{Cr}$-Si alloys. Materials Characterization. 2008;59(1):74-78.

9. Baldan R, Faria MIST, Nunes CA, Coelho GC, Chad VM, De Avillez RR. Microstructural Evidence of $\beta \mathrm{Co}_{2} \mathrm{Si}$-phase Stability in the Co-Si System. Journal of Phase Equilibria and Diffusion. 2008;29(6):477-481.

10. Nunes CA, Coelho GC, Ramos AS. On the invariant reactions in the Mo-rich portion of the Mo-Si system. Journal of Phase Equilibria. 2001;22(5):556-559.

11. Villars P, Calvert LD. Pearson's handbook of crystallographic data for intermetallic phases. 2nd ed. Materials Park: ASM International; 1991.

12. Kraus W, Nolze G. PowderCell for Windows (version 2.3). Berlin: Federal Institute for Materials Research and Testing; 1999. 